\title{
Pinpointing and Quantifying the Aluminum Distribution in Zeolite Catalysts Using Anomalous Scattering at the Al Absorption Edge
}

\author{
Ana B. Pinar, ${ }^{\perp}$ Przemyslaw Rzepka, ${ }^{\perp}$ Amy J. Knorpp, Lynne B. McCusker,* Christian Baerlocher,
} Thomas Huthwelker, and Jeroen A. van Bokhoven*

Cite This: J. Am. Chem. Soc. 2021, 143, 17926-17930

Read Online

ABSTRACT: The location of aluminum in a zeolite framework structure defines the accessibility and geometry of the catalytically active sites, but determining this location crystallographically is fraught with difficulties. Typical zeolite catalysts contain only a small amount of aluminum, and the X-ray scattering factors for silicon and aluminum are very similar. To address this problem, we have exploited the properties of resonant $\mathrm{X}$-ray powder diffraction across the $\mathrm{Al} \mathrm{K}$ edge, where the aluminum scattering factor changes dramatically. By combining conventional synchrotron powder diffraction data with those collected at energies near the X-ray absorption edge, aluminum is highlighted. In this way, the different distributions of aluminum in two FER-type zeolites with identical chemical compositions but different catalytic properties could be determined unambiguously. The results are consistent with previous studies, but quantitative. This approach constitutes a major advance in our fundamental understanding of the relationship between zeolite structure and catalytic activity.

$\mathrm{T}$ he outstanding performance of zeolites as heterogeneous acid catalysts in oil refining processes and fine chemical production stems from a combination of their robust and crystalline aluminosilicate framework structures, which have well-defined, interconnected pores of molecular dimensions, and the protons in this pore system. ${ }^{1}$ The tetrahedrally coordinated silicon and aluminum atoms ( $\mathrm{T}$ atoms) are bridged by oxygen atoms and can be arranged in many different ways to create different channel systems with different adsorption and catalytic properties. There are currently 253 confirmed zeolite framework types. ${ }^{2}$ When a silicon atom is replaced by aluminum, a local negative charge on the zeolite framework is generated, and this is balanced with a positively charged extraframework cation. ${ }^{3}$ When these are protons, the zeolite becomes an environmentally friendly solid acid that is active in Brønsted-acid-catalyzed reactions.

To understand and to fine-tune such a zeolite catalyst, it would be useful to know and control where these active sites are within the pores and thereby their accessibility and local geometries. However, it is not easy to distinguish aluminum and silicon with X-ray diffraction methods because their scattering factors are very similar (13 vs 14 electrons, Figure S1) and because the substitution of aluminum for silicon at specific sites is usually only partial (typical zeolite catalysts have $\mathrm{Si}: \mathrm{Al}$ ratios of 5 or more). At best, longer $\mathrm{T}-\mathrm{O}$ bond distances can be used to identify $\mathrm{T}$ sites containing a significant amount of aluminum ( $\mathrm{Si}-\mathrm{O} 1.60 \AA \mathrm{Al}-\mathrm{O} 1.74 \AA$ ). ${ }^{4}$ The $\mathrm{Si}: \mathrm{Al}$ contrast with neutron diffraction is only slightly better. Indeed, there is currently no general method that can identify directly which $\mathrm{T}$ sites in a zeolite framework structure are occupied by aluminum. However, a number of techniques have been applied to obtain indirect information that allows a partial resolution of the problem. These include ${ }^{27} \mathrm{Al}$ multiquantum solid-state nuclear magnetic resonance spectroscopy (MQ
MAS NMR), ${ }^{5,6}$ X-ray absorption spectroscopy (XAS), ${ }^{7}$ X-ray standing waves, ${ }^{8}$ and $\mathrm{Co}^{2+}$ ion exchange to identify the presence of aluminum atoms in close proximity to one another. ${ }^{9}$ Here we describe an approach that exploits resonant (anomalous) scattering near the $\mathrm{Al} \mathrm{K}$ edge $(1.56 \mathrm{keV}$ or 7.95 $\AA$ ) to obtain a quantitative assignment of aluminum to the $\mathrm{T}$ sites in a zeolite framework.

Anomalous X-ray diffraction (AXRD) is a well-established technique that takes advantage of the resonant scattering of an element near its absorption edge. ${ }^{10}$ At most wavelengths, the $\mathrm{X}$-ray atomic scattering factor, $f=f_{0}+f^{\prime}+i f^{\prime \prime}$, is primarily a function that reflects the number of electrons in the element $\left(f_{0}\right)$, but in the vicinity of an absorption edge, the $f^{\prime}$ and $f^{\prime \prime}$ contributions become significant and the scattering power of that element changes. Perhaps the best known application of this phenomenon is in the multiwavelength anomalous diffraction $(\mathrm{MAD})$ technique that is widely used in structural biology with single-crystal X-ray diffraction data to determine the structures of complex proteins. ${ }^{11}$ But it has also been applied to highlight other elements with absorption edges at energies suitable for diffraction experiments (e.g., $\mathrm{Br}(13.5$ $\mathrm{keV}), \mathrm{Rb}(15.2 \mathrm{keV}), \mathrm{Zn}(9.66 \mathrm{keV})$, and Fe (7.11 keV)). In zeolites, AXRD has been used to distinguish atoms in extraframework positions. ${ }^{12-14}$

Unfortunately, exploiting anomalous X-ray diffraction with powder diffraction data (AXPD) at the tender energy level of

Received: July 4, 2021

Published: October 25, 2021 
the $\mathrm{Al} \mathrm{K}$ edge $(1.56 \mathrm{keV})$ is less straightforward. In this energy range, the X-ray absorption is very high, so the experiment has to be conducted in a vacuum and in reflection mode because only a few micrometers of the sample can be penetrated before the X-rays are absorbed completely. Furthermore, with the long wavelengths in the range of $8 \AA$, only a few reflections can be measured before the diffraction limit $\left(d_{\text {min }}=\lambda / 2=4 \AA\right)$ is reached. With these issues in mind, three samples were prepared and measured on the PHOENIX II instrument at the Swiss Light Source. All technical details regarding the sample preparation and the experimental setup are given in the Supporting Information.

First, a sample of zeolite $\mathrm{A},\left|\mathrm{Na}_{12}\right|_{8}\left[\mathrm{Al}_{12} \mathrm{Si}_{12} \mathrm{O}_{48}\right]_{8}$ (framework type LTA), in which the aluminum and silicon sites are fully ordered (Figure S2), was used as a test material and a scattering factor calibration standard. Then two other zeolites with the FER-type framework structure (four $\mathrm{T}$ atoms in the asymmetric unit) were examined. Although their chemical compositions $\left(\mathrm{IH}_{2.2} \mathrm{I}\left[\mathrm{Si}_{33.8} \mathrm{Al}_{2.2} \mathrm{O}_{72}\right]\right)$ and framework structures are identical, they were synthesized under different conditions (specifically tailored to influence the $\mathrm{Al}$ distribution), and indeed they exhibit different catalytic properties. ${ }^{15}$ Conventional structure analyses ${ }^{16}$ and other techniques ${ }^{17-19}$ suggest that the aluminum atoms are differently distributed over the four $\mathrm{T}$ sites in the two materials (Figure 1), so these samples

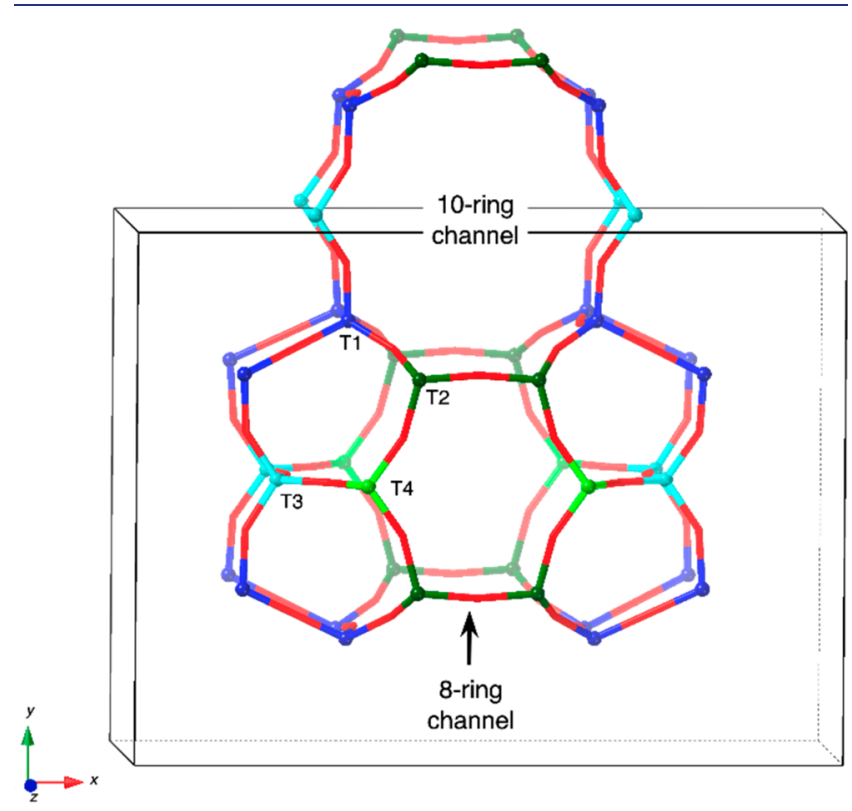

Figure 1. FER-type framework structure. The positions of the four crystallographically independent $\mathrm{T}$ sites and the 8-ring and 10-ring channels are shown.

appeared to be ideal candidates for testing not only the viability of the Al AXPD method but also, because of their high Si:Al ratios (ca. 15), its limits of detection. AXPD data were collected at several different wavelengths on all three samples. For the basic structure analyses, conventional synchrotron powder diffraction (XPD) patterns were recorded on the same samples in transmission mode $(0.5 \mathrm{~mm}$ capillary) at a wavelength of $0.77808 \AA$ on the Materials Science beamline at SLS. ${ }^{20}$ To ensure that there was no water in the samples, all were measured in situ under a flow of dry nitrogen at elevated temperatures $\left(200-400{ }^{\circ} \mathrm{C}\right)$.
For the zeolite A sample, the basic crystal structure was refined first by using the Topas software package ${ }^{21}$ and the conventional XPD pattern. Once those parameters had converged, they were fixed and the AXPD data were added as additional information. A single set of profile parameters for these data sets was refined by using as few parameters as possible (lattice parameters, peak shape, peak asymmetry, and sample displacement). To scale the different AXPD patterns to one another, two wavelength-dependent factors had to be taken into account: the penetration depth of the X-rays, and therefore the volume of sample irradiated, and the response of the detector. Initial estimates of the scale factors for the AXPD patterns were calculated by using eq 1 in the Methods section of the Supporting Information, but they were then allowed to refine individually. Once the scale and profile parameters had converged, they were also fixed. In the final step, just the aluminum occupancies were refined by using all data sets simultaneously. Refinement details and profile fits are given in Table S1 and Figure S3.

The intensity of each reflection $\left(I_{h k l}\right)$ measured in a diffraction experiment is proportional to the square of the structure factor for that reflection $\left(F_{h k l}\right)$, which in turn contains all structural information. When a sufficient number of different reflections are measured, the parameters of the atoms in the structure can be refined to find the structure that best fits the measured values. The $F_{h k l}$ values calculated for the structure of zeolite A at different energies are shown in Figure 2a. The small but significant differences arise from the change in the aluminum scattering factor near the $\mathrm{Al} \mathrm{K}$ edge. Each reflection is affected slightly differently, and these are the differences that allow the aluminum distribution to be determined.

a

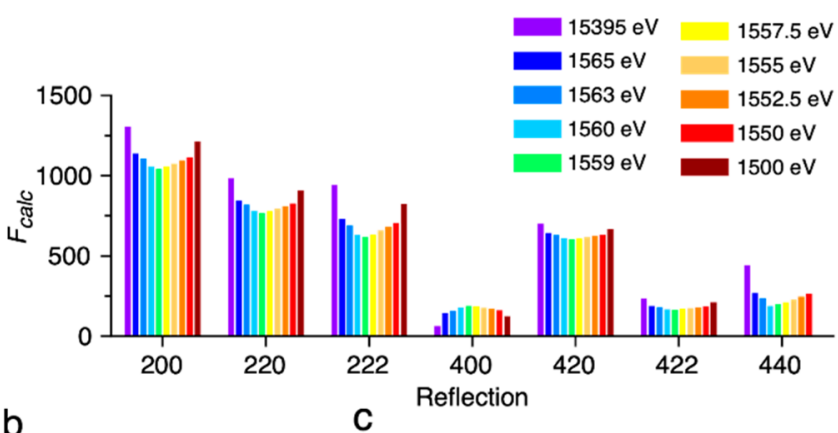

b
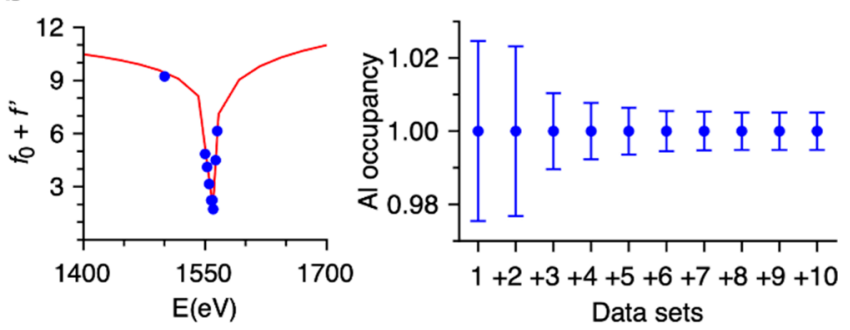

Figure 2. Refinement of zeolite A. (a) Comparison of the structure factors, $F_{h k l}$, calculated for the refined structure at different energies. (b) Real part of the aluminum form factor, $f_{0}+f^{\prime}$, showing the refined values (blue) and those from the LBL database (red). (c) Uncertainties in the refined aluminum occupancy at $\mathrm{T} 2$ as a function of the data sets used (1: $15395 \mathrm{eV} ; 2: 1500 \mathrm{eV} ; 3: 1550 \mathrm{eV}$; 4: 1552.5 eV; 5: $1555 \mathrm{eV}$; 6: $1557.5 \mathrm{eV}$;: $1559 \mathrm{eV}$; 8: $1560 \mathrm{eV;} \mathrm{9:} 1563 \mathrm{eV}$; 10: $1565 \mathrm{eV})$. 
Because the exact location of the absorption edge is sensitive to the local chemical environment of the element, the data for zeolite A were also used to calibrate the $f^{\prime}$ contribution to the atomic scattering factor $f$ at each energy. Refined values for $f^{\prime}$ were found to be very close to those in the LBL database used by Topas (Figure 2b); thus, to keep the number of refined parameters to a minimum, the LBL values were used in all subsequent refinements. Tabulated values for the $f^{\prime \prime}$ contribution, which changes abruptly at the absorption edge but is otherwise fairly constant over the energy range in question, were also applied. Even with just the conventional data set, the aluminum distribution is clear because the structure is in fact fully ordered, but by including the AXPD data sets in the refinement, the uncertainty in the aluminum occupancy factor of 1.00 for $\mathrm{T} 2$ could be reduced from 0.025 to 0.005 (Figure 2c).

A data analysis procedure similar to that used for zeolite A was applied to the two ferrierite data sets. For FER1, the initial structure refinement showed that a significant quartz impurity is present in the sample (35\%), but it could be modeled easily with only a few parameters. Four AXPD data sets, measured at $1553,1559,1561$, and $1563 \mathrm{eV}$, were used to supplement the capillary data. Once the profile parameters for the AXPD data sets had been refined and fixed, refinement of just the aluminum occupancies proved to be stable and converged with the aluminum distributed over all four T sites (Figure 3, Table S2, and Figure S4).

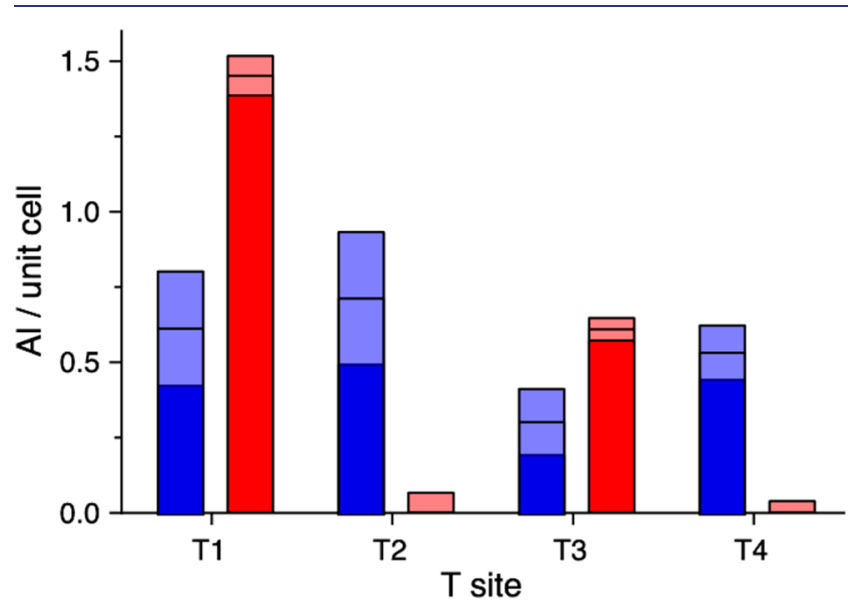

Figure 3. Distribution of aluminum in the two FER-type zeolites. The 2.2 aluminum atoms per unit cell in FER1 (blue) and FER-PYRR (red) are distributed differently over the four $\mathrm{T}$ sites. The lighter color indicates the range of error and the horizontal line the refined value.

For FER-PYRR, the structure refinement using the conventional data set showed that there are stacking faults present. This is a well-documented occurrence in ferrierite materials. ${ }^{22}$ Fortunately, a simple model that involved no additional positional parameters could be constructed $\left(x^{\prime}=x ; y^{\prime}=y ; z^{\prime}=\right.$ $z+1 / 2)$, and the percentage of this second framework structure refined to just $5 \%$ of the total scattering. A further complication was that a small but significant preferred orientation of the plate-like FER-PYRR crystallites along the [100] direction was apparent, so a simple March-Dollase correction was applied. At this point, the aluminum was assumed to be distributed evenly over all four $\mathrm{T}$ sites. Three AXPD data sets were measured close to the $\mathrm{Al} \mathrm{K}$ edge at 1553 , 1559, and $1563 \mathrm{eV}$. As might be expected for a flat-plate sample, the preferential orientation of the crystallites along [100] was even more pronounced in the AXPD sample, but the effect could still be modeled by using a March-Dollase correction. Refinement of the aluminum occupancies showed that the 2.2 aluminum atoms per unit cell are clearly concentrated in the T1 and T3 sites (Figure 3, Table S3, and Figure S5). As elemental analysis showed that there are 2.2 aluminum atoms per unit cell in both FER1 and FERPYRR, ${ }^{15,16}$ this was introduced as a restraint in both refinements. A comparison of the structure factors calculated for the two structures at the different energies (Figure S6) and structural data for all three refinements are provided in the Supporting Information.

Ferrierite is a well-known catalyst for hydrocarbon isomerization, ${ }^{23-25}$ cracking, ${ }^{26-28}$ and pyrolysis. ${ }^{29}$ For the samples studied here, FER1 is more active in the isomerization of $n$ butene to $i$-butene than is FER-PYRR ( $40 \%$ and $14 \%$, respectively $)^{15,30}$ but less selective $(25 \%$ vs $57 \%$ initially and $38 \%$ vs $97 \%$ after $12 \mathrm{~h}$ on stream). ${ }^{30}$ It also deactivates much faster, presumably because the number of active sites in the 10ring channels leads to oligomerization and coking. ${ }^{30}$ This can be understood in view of the aluminum ordering found in the two ferrierite structures. The higher activity and faster deactivation of FER1 are due to the higher proportion of active sites at T2 in the accessible 10-ring channels. Earlier structural studies showed that pyrrolidine in the ferrierite cavity is associated with the oxygens linking two T1 or two T3 sites (O3 and $\mathrm{O} 8$, respectively). ${ }^{16}$ This means that the protons left after calcination are likely to be associated with these $\mathrm{O}$ atoms and therefore not accessible in the 10-ring channel. However, in the FER1 synthesis, where $\mathrm{Na}^{+}$ions are also present, $\mathrm{Al}$ is also found in the $\mathrm{T} 2$ and $\mathrm{T} 4$ sites. Protons associated with the $\mathrm{O}$ atoms around $\mathrm{T} 2$ are accessible for reaction in the 10-ring channel. The concentration of aluminum at the T1 and T3 sites in the FER-PYRR structure is completely in line with the structural study mentioned above $^{16}$ and previous X-ray emission spectroscopy, ${ }^{17} \mathrm{MQ}$ MAS NMR, ${ }^{9,18}$ heat of adsorption, ${ }^{19}$ and computational studies $^{31}$ performed on the same samples. The advantage of the AXPD characterization is that it is also quantitative.

By combining conventional X-ray powder diffraction data with diffraction data collected at the $\mathrm{Al} \mathrm{K}$ edge, the distribution of aluminum over the $\mathrm{T}$ sites in a zeolite framework structure can be determined quantitatively and unambiguously. The results of this kind of analysis on two FER-type zeolites demonstrate that the method can be applied even for zeolites with $\mathrm{Si}$ :Al ratios as high as 15 . It would appear from the structure factor calculations shown in Figure S6 that differences in the structure factors of the order of just $1-2 \%$ from those calculated for a random distribution of aluminum lead to a successful refinement. The more the aluminum is concentrated in just a few of the available $\mathrm{T}$ sites (as for example in FER-PYRR), the larger these differences. In such cases, zeolites with higher $\mathrm{Si}$ :Al ratios could fall within the detection limit. The method enables a quantitative characterization of the catalytically active sites in a zeolitic material, and that in turn allows the activity of that zeolite to be understood and fine-tuned. This constitutes a major step forward in our fundamental understanding of the relationship between zeolite structure and catalytic activity. We believe that AXPD at the Al $\mathrm{K}$ edge could become the technique of choice for zeolite scientists interested in locating the active catalytic sites in their materials. 


\section{ASSOCIATED CONTENT}

\section{(s) Supporting Information}

The Supporting Information is available free of charge at https://pubs.acs.org/doi/10.1021/jacs.1c06925.

Methods, details of the structure refinements, the Rietveld refinement profiles, structure factor comparisons for different energies, and structural data for zeolite A, FER1, and FER-PYRR (PDF)

\section{AUTHOR INFORMATION}

\section{Corresponding Authors}

Jeroen A. van Bokhoven - Laboratory for Catalysis and Sustainable Chemistry, Paul Scherrer Institut (PSI), 5232 Villigen, Switzerland; Institute for Chemical and Bioengineering, ETH Zurich, 8093 Zurich, Switzerland; () orcid.org/0000-0002-4166-2284;

Email: jeroen.vanbokhoven@chem.ethz.ch

Lynne B. McCusker - Department of Materials, ETH Zurich, 8093 Zurich, Switzerland; (1) orcid.org/0000-0003-00741733; Email: mccusker@mat.ethz.ch

\section{Authors}

Ana B. Pinar - Laboratory for Catalysis and Sustainable Chemistry, Paul Scherrer Institut (PSI), 5232 Villigen, Switzerland

Przemyslaw Rzepka - Laboratory for Catalysis and Sustainable Chemistry, Paul Scherrer Institut (PSI), 5232 Villigen, Switzerland; Institute for Chemical and Bioengineering, ETH Zurich, 8093 Zurich, Switzerland; (1) orcid.org/0000-0003-3185-3535

Amy J. Knorpp - Institute for Chemical and Bioengineering, ETH Zurich, 8093 Zurich, Switzerland

Christian Baerlocher - Institute for Chemical and Bioengineering, ETH Zurich, 8093 Zurich, Switzerland

Thomas Huthwelker - Swiss Light Source, Paul Scherrer Institut (PSI), 5232 Villigen, Switzerland

Complete contact information is available at: https://pubs.acs.org/10.1021/jacs.1c06925

\section{Author Contributions}

${ }^{\perp}$ A.B.P. and P.R. contributed equally to this work.

\section{Notes}

The authors declare no competing financial interest.

\section{ACKNOWLEDGMENTS}

We thank Dr. Camelia Borca for technical support and discussions before and during the measurements and Reto Wetter and Christophe Frieh for technical support regarding the diffractometer setup. We also thank Dr. Nicola Casati for assistance with the in situ capillary measurements and acknowledge the Paul Scherrer Institute, Villigen, Switzerland, for provision of synchrotron radiation beam time on the PHOENIX and MS-Powder beamlines. A.B.P. and J.A.v.B. thank the Energy System Integration platform of the Paul Scherrer Institute for financial support.

\section{REFERENCES}

(1) Čejka, J.; Morris, R. E.; Serrano, D. P. Catalysis on Zeolites Catalysis Science \& Technology. Catal. Sci. Technol. 2016, 6, 24652466.

(2) Baerlocher, C.; McCusker, L. B. Database of zeolite structures; http://www.iza-structure.org/databases/ (accessed 2018-02-15).
(3) Li, J.; Corma, A.; Yu, J. Synthesis of New Zeolite Structures. Chem. Soc. Rev. 2015, 44 (20), 7112-7127.

(4) Baur, W. H.; Fischer, R. X. The Floppiness of It All: Bond Lengths Change with Atomic Displacement Parameters and the Flexibility of Various Coordination Tetrahedra in Zeolitic Frameworks. An Empirical Structural Study of Bond Lengths and Angles. Chem. Mater. 2019, 31 (7), 2401-2420.

(5) van Bokhoven, J. A.; Koningsberger, D. C.; Kunkeler, P.; van Bekkum, H.; Kentgens, A. P. M. Stepwise Dealumination of Zeolite Beta at Specific T-Sites Observed with ${ }^{27} \mathrm{Al}$ MAS and ${ }^{27} \mathrm{Al}$ MQ MAS NMR. J. Am. Chem. Soc. 2000, 122 (51), 12842-12847.

(6) Sklenak, S.; Dědeček, J.; Li, C.; Wichterlová, B.; Gábová, V.; Sierka, M.; Sauer, J. Aluminum Siting in Silicon-Rich Zeolite Frameworks: A Combined High-Resolution ${ }^{27} \mathrm{Al}$ NMR Spectroscopy and Quantum Mechanics/Molecular Mechanics Study of ZSM-5. Angew. Chem. 2007, 119 (38), 7424-7427.

(7) Vjunov, A.; Fulton, J. L.; Huthwelker, T.; Pin, S.; Mei, D.; Schenter, G. K.; Govind, N.; Camaioni, D. M.; Hu, J. Z.; Lercher, J. A. Quantitatively Probing the Al Distribution in Zeolites. J. Am. Chem. Soc. 2014, 136 (23), 8296-8306.

(8) van Bokhoven, J. A.; Lee, T.-L.; Drakopoulos, M.; Lamberti, C.; Thieß, S.; Zegenhagen, J. Determining the Aluminum Occupancy on the Active T-Sites in Zeolites Using X-Ray Standing Waves. Nat. Mater. 2008, 7 (7), 551-555.

(9) Dědeček, J.; Lucero, M. J.; Li, C.; Gao, F.; Klein, P.; Urbanova, M.; Tvaruzkova, Z.; Sazama, P.; Sklenak, S. Complex Analysis of the Aluminum Siting in the Framework of Silicon-Rich Zeolites. A Case Study on Ferrierites. J. Phys. Chem. C 2011, 115 (22), 11056-11064.

(10) Grenier, S.; Joly, Y. Basics of Resonant Elastic X-Ray Scattering Theory. J. Phys.: Conf. Ser. 2014, 519 (1), 012001.

(11) Hendrickson, W. A. Determination of Macromolecular Structures from Anomalous Diffraction of Synchrotron Radiation. Science 1991, 254 (5028), 51-58.

(12) Goldbach, A.; Saboungi, M.-L.; Iton, L.; Price, D. L. Stabilization of Selenium in Zeolites: An Anomalous X-Ray Scattering Study. Chem. Commun. 1999, 997-998.

(13) Pichon, C.; Palancher, H.; Rebours, B.; Lynch, J.; Bérar, J. F.; Hodeau, J. L. In Situ Characterisation by Anomalous X-Ray Diffraction of the Cationic Distribution of Dehydrated SrRbX Zeolite. Stud. Surf. Sci. Catal. 2004, 154, 1641-1648.

(14) Jones, R. H.; Lightfoot, P.; Ormerod, R. M. The Location of Sorbed $\mathrm{Kr}$ in Silicalite Using Resonant X-Ray Diffraction. J. Phys. Chem. Solids 1995, 56 (10), 1377-1381.

(15) Pinar, A. B.; Márquez-Álvarez, C.; Grande-Casas, M.; PérezPariente, J. Template-Controlled Acidity and Catalytic Activity of Ferrierite Crystals. J. Catal. 2009, 263 (2), 258-265.

(16) Pinar, A. B.; Gómez-Hortigüela, L.; McCusker, L. B.; PérezPariente, J. Controlling the Aluminum Distribution in the Zeolite Ferrierite via the Organic Structure Directing Agent. Chem. Mater. 2013, 25 (18), 3654-3661.

(17) Bohinc, R.; Hoszowska, J.; Dousse, J. C.; Blachucki, W.; Zeeshan, F.; Kayser, Y.; Nachtegaal, M.; Pinar, A. B.; van Bokhoven, J. A. Distribution of Aluminum over Different T-Sites in Ferrierite Zeolites Studied with Aluminum Valence to Core X-Ray Emission Spectroscopy. Phys. Chem. Chem. Phys. 2017, 19 (43), 29271-29277.

(18) Pinar, A. B.; Verel, R.; Pérez-Pariente, J.; van Bokhoven, J. A. Direct Evidence of the Effect of Synthesis Conditions on Aluminum Siting in Zeolite Ferrierite: $\mathrm{A}^{27} \mathrm{Al}$ MQ MAS NMR Study. Microporous Mesoporous Mater. 2014, 193, 111-114.

(19) Nachtigall, P.; Grajciar, L.; Pérez-Pariente, J.; Pinar, A. B.; Zukal, A.; Čejka, J. Control of $\mathrm{CO}_{2}$ Adsorption Heats by the Al Distribution in FER Zeolites. Phys. Chem. Chem. Phys. 2012, 14 (3), 1117-1120.

(20) Willmott, P. R.; Meister, D.; Leake, S. J.; Lange, M.; Bergamaschi, A.; Böge, M.; Calvi, M.; Cancellieri, C.; Casati, N.; Cervellino, A.; et al. The Materials Science Beamline Upgrade at the Swiss Light Source. J. Synchrotron Radiat. 2013, 20 (5), 667-682. 
(21) Coelho, A. A. TOPAS and TOPAS-Academic: An Optimization Program Integrating Computer Algebra and Crystallographic Objects Written in C++. J. Appl. Crystallogr. 2018, 51 (1), 210-218.

(22) Gramlich-Meier, R.; Meier, W. M.; Smith, B. K. On Faults in the Framework Structure of the Zeolite Ferrierite. Zeitschrift fur Krist. - New Cryst. Struct. 1984, 169 (1-4), 201-210.

(23) Föttinger, K.; Kinger, G.; Vinek, H. 1-Pentene Isomerization over FER and BEA. Appl. Catal., A 2003, 249 (2), 205-212.

(24) Meunier, F. C.; Domokos, L.; Seshan, K.; Lercher, J. A. In Situ IR Study of the Nature and Mobility of Sorbed Species on H-FER during but-1-Ene Isomerization. J. Catal. 2002, 211 (2), 366-378.

(25) Pellet, R. J.; Casey, D. G.; Huang, H. M.; Kessler, R. V.; Kuhlman, E. J.; O’Young, C. L.; Sawicki, R. A.; Ugolini, J. R. Isomerization of n-Butene to Isobutene by Ferrierite and Modified Ferrierite Catalysts. J. Catal. 1995, 157 (2), 423-435.

(26) Anderson, B. G.; Schumacher, R. R.; van Duren, R.; Singh, A. P.; van Santen, R. A. An Attempt to Predict the Optimum ZeoliteBased Catalyst for Selective Cracking of Naphtha-Range Hydrocarbons to Light Olefins. J. Mol. Catal. A: Chem. 2002, 181 (1-2), 291-301.

(27) Peixoto, D. P. B.; Cabral de Menezes, S. M.; Pais da Silva, M. I. Influence of Different Processes of Dealumination on Acid Properties of an H-Ferrierite Zeolite. Mater. Lett. 2003, 57 (24-25), 39333942.

(28) Lee, Y.; Park, M. B.; Kim, P. S.; Vicente, A.; Fernandez, C.; Nam, I. S.; Hong, S. B. Synthesis and Catalytic Behavior of Ferrierite Zeolite Nanoneedles. ACS Catal. 2013, 3 (4), 617-621.

(29) Bonilla, A.; Baudouin, D.; Pérez-Ramírez, J. Desilication of Ferrierite Zeolite for Porosity Generation and Improved Effectiveness in Polyethylene Pyrolysis. J. Catal. 2009, 265 (2), 170-180.

(30) Márquez-Alvarez, C.; Pinar, A. B.; García, R.; Grande-Casas, M.; Pérez-Pariente, J. Influence of Al Distribution and Defects Concentration of Ferrierite Catalysts Synthesized from Na-Free Gels in the Skeletal Isomerization of n-Butene. Top. Catal. 2009, 52 (9), 1281-1291.

(31) Gómez-Hortigüela, L.; Pinar, A. B.; Corà, F.; Pérez-Pariente, J. Dopant-Siting Selectivity in Nanoporous Catalysts: Control of Proton Accessibility in Zeolite Catalysts through the Rational Use of Templates. Chem. Commun. 2010, 46 (12), 2073-2075. 